\title{
Justificativa e proposta de indicador de sustentabilidade financeira
}

\section{Justificative and proposal of indicator of financial sustainability}

\section{Miriane de Almeida Fernandes}

Mestre em Administração pela FACCAMP

Professora da Faculdade Anhanguera de Campinas

Endereço: Rua Pandia Calógeras, $\mathrm{n}^{\circ}$ 51, Apto 11

CEP: 13024-170 - Campinas, SP - Brasil

E-mail: miriane.fernandes@aedu.com

Telefone: (19) 3512-4500 e (19) 9144-9922

\section{Manuel Meireles}

Doutor em Engenharia de Produção pela Universidade São Paulo

Professor e pesquisador do Programa de Mestrado Profissional da FACCAMP

Endereço: Alameda Dracenas, ${ }^{\circ}$ 16, Caixa postal 110

CEP: $18147-000$ - Araçariguama/SP - Brasil

E-mail: profmeireles@uol.com.br

Telefone: (11) 4136-2675

Artigo recebido em 26/02/2012. Revisado por pares em 01/03/2013. Reformulado em 30/03/2013. Recomendado para publicação em 31/05/2013 por Sandra Rolim Ensslin (Editora Científica). Publicado em 09/08/2013. 


\title{
Resumo
}

Este trabalho propõe um modelo de indicador de sustentabilidade financeira, isto é, um indicador capaz de medir a capacidade de uma entidade econômica de autoprover recursos financeiros para enfrentar contratempos decorrentes da sua exploração econômica, que se articula sobre a autonomia financeira, o equilíbrio do crescimento e o nível de negócio. $\mathrm{O}$ trabalho é uma nova proposta no campo da análise das demonstrações financeiras. A adequabilidade do indicador foi testada com uma amostra de 41 empresas contabilmente estruturadas da região do município de Campinas (SP). Os testes mostraram diferenças significativas no que concerne à autonomia financeira.

Palavras-chave: Indicador de sustentabilidade financeira. Indicadores financeiros. Análise das demonstrações contábeis.

\begin{abstract}
This study proposes an indicator model of financial sustainability, that is, an indicator which is capable to measure the capacity of an economic entity to auto provide financial resources. This is so in order to face current setbacks of its economic exploration that is articulated on the financial autonomy, on the balance of the growth and on the business level. The present study is a new proposal in the field of Financial Demonstrations analysis. The suitability of the indicator was tested with a sample of 41 accountant-structured companies in Campinas city area (in the state of São Paulo-SP). The tests showed significant differences in relation to their financial autonomy.
\end{abstract}

Keywords: Financial sustainability indicator. Financial indicators. Accounting demonstrations analysis.

\section{Introdução}

O presente trabalho tem por objetivo propor e mostrar a aplicabilidade de um indicador de sustentabilidade financeira. Cabe ressaltar que a sustentabilidade financeira tem sido depreendida pela aplicação de outros indicadores, especialmente por aqueles associados à falência das empresas. Por isso, ressalta-se os casos de Beaver (1966), que propôs um modelo de previsão de dificuldade financeira, e de Altman (1968), que demonstrou que a falência de uma empresa poderia ser prevista por meio das informações disponíveis nos balanços patrimoniais.

O que se propõe neste trabalho é um indicador específico para avaliar a sustentabilidade financeira, isto é, a capacidade de uma entidade de autoprover recursos financeiros para enfrentar contratempos decorrentes da sua exploração econômica.

Nesse sentido, o indicador aqui proposto, que mede a capacidade de uma entidade de autoprover recursos financeiros para enfrentar contratempos, difere de indicadores associados 
à possibilidade de uma entidade soçobrar, embora se possa associar a falência de uma empresa à falta de sustentabilidade financeira.

Beaud (1997, p. 63) afirma que um trabalho científico deve contribuir, mesmo que modestamente, para o aprimoramento, para a ampliação ou para o aprofundamento do conhecimento dentro do domínio da sua competência. Dessa forma, discute-se, aqui, o constructo "indicador de sustentabilidade financeira" e se mostra a aplicação do indicador de sustentabilidade financeira como técnica para extrair informações em um contexto de tomada de decisão financeira.

O artigo está organizado da seguinte forma: além desta (i) parte introdutória, a (ii) de revisão da literatura, que discutirá os conceitos de sustentabilidade, sustentabilidade financeira e indicador; em (iii) tem-se a seção que apresentará o modelo de indicador que é proposto; e (iv) a seção que tratará da metodologia da pesquisa. Finalmente, em (v), serão apresentados os resultados e a análise e (vi), a última seção, tecerá as considerações finais.

\title{
2 Revisão da Literatura
}

A proposta de um indicador de sustentabilidade financeira requer que se aborde os seguintes construtos: sustentabilidade, sustentabilidade financeira e indicador.

Martins e Silva (2005) afirmam que

\begin{abstract}
contrariamente ao que ocorre nas ciências naturais onde conceitos, definições e constructos são suficientemente claros, precisos e universais, nas ciências sociais aplicadas - nesse caso, Contabilidade e Controladoria - tais elementos estão distantes de padronizações e universalizações, carecendo de esforços de pesquisadores na busca de superação, ou mesmo adequação aos problemas advindos desses fatos." É o que ocorre com o conceito “indicador de sustentabilidade financeira.
\end{abstract}

O constructo sustentabilidade financeira, com a especificidade do termo, não foi encontrado em fonte alguma. Há menções ao termo, mas nos contextos de sustentabilidade econômica, social ou ecológica. E não é isso o que decididamente se pretende aqui.

O conceito de indicador de sustentabilidade financeira não é um indicador de sustentabilidade organizacional, como preconiza Ramos Filho (2000) quando afirma que a sustentabilidade organizacional seria especialmente relacionada à gestão de pessoas e se articularia sobre o tripé: performance, conhecimento e sinergia.

Também não é um constructo associado ao Triple Bottom Line (TBL) da sustentabilidade de um negócio. O Conceito TBL, afirmam Vellani e Ribeiro (2009), reflete sobre a necessidade de as empresas ponderarem em suas decisões estratégicas, mantendo a sustentabilidade econômica ao gerenciar empresas lucrativas e geradoras de valor; a sustentabilidade social ao estimular a educação, cultura, lazer e justiça social à comunidade; e a sustentabilidade ecológica ao manter ecossistemas vivos, com diversidade.

A sustentabilidade financeira também não é algo simplesmente relacionado a custos ambientais, mas evidenciados nos relatórios de administração e notas explicativas das empresas que compõe o Índice de Sustentabilidade Empresarial (ISE), como mostram Rover, Borba e Borgert (2008). Embora muitos indicadores econômico-financeiros forneçam indícios do grau de sustentabilidade financeira da entidade, é necessário ter presente esse conceito e 
ver como um conjunto articulado de indicadores pode, de alguma forma, medi-la e expressála.

\subsection{Conceitos de "sustentabilidade" $e$ "sustentabilidade financeira"}

Para se conceituar sustentabilidade financeira, é preciso ter em conta, inicialmente, o conceito de sustentabilidade. Esse termo conta com vários exemplos de definições: Liverman et al. (1988), Dovers e Handmer (1993), Moore e Johnson (1994) e Bartuska, Kazimee e Owen (1998). Entretanto, o conceito de Conway (1986) apresenta-se de forma simples e resumida, porém, sendo suficiente para a interpretação do termo: "sustentabilidade é a habilidade de um sistema em manter sua produtividade quando este se encontra sujeita a intenso esforço ou alterações".

Friedman $(2010$, p. 77$)$ afirma que a sustentabilidade prega que a empresa se comportará como se fosse permanecer para sempre e será sempre responsável pelo que acontecer.

O conceito utilizado no Relatório de Brundtland (1987) afirma que desenvolvimento sustentável é aquele que atende à necessidade das gerações atuais, sem comprometer a capacidade de as futuras gerações terem suas próprias necessidades atendidas.

A característica fundamental do conceito "sustentabilidade" reside, portanto, na qualidade de se manter para sempre, como afirmam Valadão Jr., Malaquias e Sousa (2008). Essa característica é a mesma declarada por Araújo (2003, p. 3), que afirma que sustentabilidade é a capacidade de ser um empreendimento capaz de se manter mais ou menos constante ou estável, por um longo período, sendo tal estabilidade em termos institucionais, técnicos, políticos e financeiros.

Ampliando-se o conceito de "sustentabilidade", chega-se ao conceito de "sustentabilidade financeira". Tendo Conway (1986) e Ramos Filho (2000) como base, ampliando e adequando o conceito geral de sustentabilidade, define-se, aqui, o conceito específico de sustentabilidade financeira de uma entidade econômica como a capacidade dessa entidade autoprover recursos financeiros para enfrentar contratempos decorrentes da sua exploração econômica, que se articula sobre a autonomia financeira, o equilíbrio do crescimento e o nível de negócio.

\subsection{Conceito de "indicador"}

Outro conceito que este trabalho aborda é o conceito de indicador. O termo indicador origina-se do latim indicare, verbo que significa apontar ou proclamar. Em português, indicador significa aquilo que indica, torna patente, revela, propõe, sugere, expõe, menciona, aconselha, lembra. Um indicador, segundo Cavalcanti (2003), é algo que auxilia na transmissão de um conjunto de informações sobre complexos processos, eventos ou tendências.

Os indicadores, segundo Hronec (1994, p. 5), possuem algumas características importantes: a) devem induzir a estratégia em toda a organização e são, portanto, top/down, devendo induzir os comportamentos desejados nos funcionários ou outros prestadios da empresa; b) devem ser adequados para responder ao gestor se ele está ou não atingindo suas metas, isto é, devem informar às pessoas como elas estão se saindo (individualmente e em 
grupo), comunicando os resultados das ações realizadas (projetos e processos); c) devem reduzir a dissonância de focos - desentendimentos quanto ao que é ou não importante; e d) devem disseminar o uso universal de conceitos (linguagem comum). Na construção do indicador de sustentabilidade financeira, foram consideradas essas características. Também se levou em conta o contexto de aplicação do indicador proposto para a tomada de decisão na esfera financeira e administrativa.

Dutra (2005), ao fazer a análise de metodologias para avaliar o desempenho organizacional, considera um conjunto de dimensões que podem ser aplicadas ao indicador proposto, já que ele considera um aspecto do desempenho organizacional de uma entidade. As dimensões propostas por Dutra são: Grau de Personalização, Grau de não Ambiguidade, Grau de Priorização, Grau de Flexibilidade, Grau de Geração de Conhecimento e Grau de Geração de Aperfeiçoamento.

\section{Modelo Proposto}

$\mathrm{O}$ indicador de sustentabilidade financeira (ISF) aqui proposto é derivado do conceito de sustentabilidade financeira, conforme foi declarado anteriormente, como a capacidade de a empresa autoprover recursos financeiros para enfrentar contratempos decorrentes da sua exploração econômica.

O ISF é um indicador fundamentado em múltiplas variáveis, como ilustra a figura 1, tais como: equilíbrio do crescimento, autonomia financeira e trading (nível de negócio).

O modelo que aqui se propõe é ilustrado por valores extraídos de diversas demonstrações financeiras, as quais podem ser encontradas nos estudos de Morante e Jorge (2010). Esses exemplos proporcionam uma fonte didática adequada e de fácil acesso.

Figura 1 - Estrutura do Indicador de Sustentabilidade Financeira de uma empresa

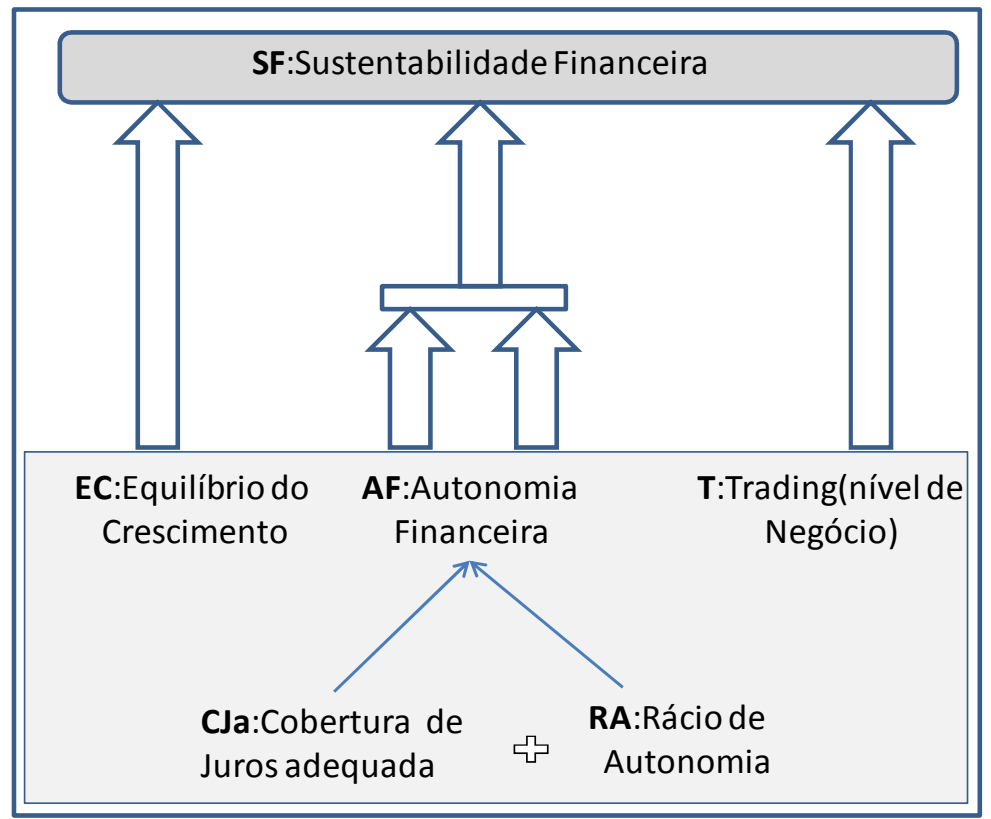

Fonte: Elaborada pelos autores. 
Para a compreensão do indicador, é necessário abordar a constituição de cada um dos seus elementos: autonomia financeira, equilíbrio do crescimento e trading.

\subsection{Autonomia Financeira}

De acordo com Walsh (2004, p. 144), autonomia financeira significa a capacidade de resistência de uma empresa a contratempos operacionais. A autonomia financeira é constituída por um índice composto por dois indicadores: um indicador derivado da cobertura de juros (CJ) e outro do rácio da autonomia.

Walsh (2004, p. 145) afirma que a cobertura de juros é um indicador recente e único, considerando que é uma medida que deriva exclusivamente da conta de ganhos e perdas:

$$
C J=\frac{L A I R+D F}{D F}
$$

Onde:

CJ é a Cobertura de Juros;

LAIR é o Lucro antes do IR e da CS; e

DF são as despesas financeiras.

Continuando a análise sobre os estudos do autor, é possível afirmar que suas pesquisas mostraram que poucas vezes empresas bem-sucedidas funcionam com um $\mathrm{CJ}<3,3$. Um valor prudente para uma empresa é de $C J \geq 5,0$ pelo que se estabelece:

$$
C J_{a}=\frac{L A I R+D F}{5 * D F}
$$

Uma cobertura de juros pode se dizer adequada se $\mathrm{CJ}_{\mathrm{a}} \geq 1,0 . \mathrm{Um}_{\mathrm{CJ}} \mathrm{J}=1$ significa que as despesas financeiras estão adequadamente cobertas pelas operações que as originam. Havendo receitas financeiras, é óbvio que a variável DF representará as despesas financeiras líquidas.

O rácio de autonomia, para Walsh (2004, p. 146), é uma das medidas mais fundamentais das finanças empresariais: "é o maior teste à autonomia financeira de uma empresa. Embora universalmente utilizado, aparece, infelizmente, sob muitos nomes diferentes e com diversos métodos de cálculo".

O rácio de autonomia (RA) é assim calculado:

$$
R A=\frac{P}{2 *(P C+E L P)}
$$

Onde:

RA é o Rácio de Autonomia; 
P é o total do passivo;

PC é o Passivo Circulante; e

PNC é o Passivo Não Circulante.

Um $\mathrm{RA}=1$ significa que seu patrimônio líquido é igual à soma dos exigíveis.

A autonomia financeira (AF), cabe lembrar, é um indicador construído com os dois índices acima, ambos contribuindo com o mesmo peso:

$$
A F=\frac{C J_{a}+R A}{2}=\frac{\frac{L A I R+D F}{5 * D F}+\frac{P}{2 *(P C+P N C)}}{2}
$$

Onde:

AF é a Autonomia Financeira;

$\mathrm{CJ}_{\mathrm{a}}$ é a Cobertura de Juros adequada;

LAIR é o Lucro antes do IR e da CS;

DF são as despesas financeiras;

P é o total do passivo;

PC é o Passivo Circulante; e

PNC é o Passivo Não Circulante.

Quadro 1 - Alguns índices de Autonomia Financeira

\begin{tabular}{|c|c|c|c|}
\hline \multicolumn{4}{|c|}{ Autonomia Financeira } \\
\hline \multicolumn{2}{|c|}{\begin{tabular}{l|l} 
Empresa com lucros \\
\end{tabular}} & \multicolumn{2}{|c|}{ Empresa com excesso de custos e despesas } \\
\hline Cja $=$ & 1.030 & Cja $=$ & 0.167 \\
\hline RA & 2.276 & RA & 0.581 \\
\hline Autonomia Financeira= & 2.276 & Autonomia Financeira $=$ & 0.581 \\
\hline \multicolumn{2}{|c|}{ Empresa com prejuízos } & \multicolumn{2}{|c|}{ Empresa com capital de giro } \\
\hline Cja= & -0.154 & Cja= & 0.336 \\
\hline RA & 0.115 & RA & 0.734 \\
\hline Autonomia Financeira= & 0.115 & Autonomia Financeira $=$ & 0.734 \\
\hline \multicolumn{2}{|c|}{ Empresa com dívidas } & \multicolumn{2}{|c|}{ Empresa sem capital de giro } \\
\hline Cja= & -0.218 & $\mathrm{Cja}=$ & -0.281 \\
\hline RA & 0.355 & RA & 0.253 \\
\hline Autonomia Financeira= & 0.355 & Autonomia Financeira= & 0.253 \\
\hline \multicolumn{2}{|c|}{ Empresa sem dívidas } & \multicolumn{2}{|c|}{ Empresa com ciclo financeiro excessivo } \\
\hline Cja= & 4.648 & $\mathrm{Cja}=$ & 0.211 \\
\hline RA & 1.549 & RA & 0.568 \\
\hline Autonomia Financeira= & 1.549 & Autonomia Financeira= & 0.568 \\
\hline
\end{tabular}

Fonte: Dados da pesquisa.

$\mathrm{Um} \mathrm{AF}=1$ significa que a empresa tem despesas financeiras adequadamente cobertas pelas operações que as originam. Significa, também, que a participação de capitais de terceiros na empresa é menor do que a participação dos acionistas. O Quadro 1 mostra alguns 
exemplos de índices de AF calculados com base nas demonstrações financeiras extraídas de Morante e Jorge (2010). É importe observar que apenas a "empresa com lucros" e a "empresa sem dívidas" apresentam $\mathrm{AF}>1$.

\subsection{Equilíbrio do Crescimento}

Para Walsh (2004, p. 214), a expressão "equilíbrio do crescimento" (EC) identifica a taxa de crescimento que uma empresa consegue sustentar com o seu fluxo de caixa operacional.

O EC é assim calculado, de acordo com Walsh (2004, p. 212):

$$
E C=\frac{R}{T}
$$

Onde:

EC é o Equilíbrio de Crescimento

$\mathrm{R}=$ Lucros retidos/vendas; e

$\mathrm{T}=$ Ativo circulante/vendas.

Admita-se, a título de exemplo, que $\mathrm{R}=0,60$ e $\mathrm{T}=0,83$. $\mathrm{O}$ valor $\mathrm{R}$ mostra que para cada $1 \$$ de vendas, a empresa gera $\$ 0.60$ de lucros retidos; o valor T, por outro lado, mostra que para cada $1 \$$ de vendas, a empresa requer $\$ 0.83$ para se realizar. A divisão $R / T=0,72$, de acordo com Walsh (2004, p. 212), dá a taxa de crescimento do ativo circulante que a empresa consegue financiar com os lucros retidos (LR).

$\mathrm{Na}$ medida em que as variáveis $\mathrm{R}$ e $\mathrm{T}$ possuem o mesmo denominador, o equilíbrio de crescimento pode-se escrever da seguinte maneira:

$$
E C=\frac{R}{T}=\frac{\frac{L R}{V}}{\frac{A C}{V}}=\frac{L R}{A C}
$$

$\mathrm{O}$ índice EC indica o quanto o crescimento é financiado por recursos próprios, sendo que um $\mathrm{EC}=1$ significa que o crescimento é financiado totalmente por recursos internos; e um valor negativo para EC indica que o crescimento da empresa está declinado.

O Quadro 2 mostra alguns exemplos de índices de EC calculados com base nas demonstrações financeiras extraídas de Morante e Jorge (2010). Cabe observar que a "empresa com dívidas", a "empresa com excesso de custos e despesas" e a "empresa sem capital de giro" apresentam EC $<1$, o que demonstra uma situação de declínio. $\mathrm{Na}$ "empresa com lucros", 0,721 do crescimento é financiado por recursos próprios. 


\begin{tabular}{|c|c|c|c|}
\hline \multicolumn{4}{|c|}{ Quadro 2 - Alguns índices de Equilíbrio do Crescimento } \\
\hline \multicolumn{4}{|c|}{ Equilíbrio do Crescimento } \\
\hline \multicolumn{2}{|l|}{ Empresa com lucros } & \multicolumn{2}{|c|}{ Empresa com excesso de custos e despesas } \\
\hline $\mathrm{R}=$ Lucros retidos/vendas & 0.598 & $\mathrm{R}=$ Lucros retidos/vendas & -0.918 \\
\hline $\mathrm{T}=$ Ativo circulante/vendas & 0.829 & $\mathrm{~T}=$ Ativo circulante/vendas & 0.525 \\
\hline Equilíbrio de crescimento $\mathrm{G}=\mathrm{R} / \mathrm{T}$ & 0.721 & Equilíbrio de crescimento $\mathrm{G}=\mathrm{R} / \mathrm{T}$ & -1.748 \\
\hline \multicolumn{2}{|l|}{ Empresa com prejuízos } & \multicolumn{2}{|c|}{ Empresa com capital de giro } \\
\hline $\mathrm{R}=$ Lucros retidos/vendas & 0.000 & $\mathrm{R}=$ Lucros retidos/vendas & 0.175 \\
\hline T=Ativo circulante/vendas & 0.200 & $\mathrm{~T}=$ Ativo circulante/vendas & 0.307 \\
\hline Equilíbrio de crescimento $\mathrm{G}=\mathrm{R} / \mathrm{T}$ & 0.000 & Equilíbrio de crescimento $\mathrm{G}=\mathrm{R} / \mathrm{T}$ & 0.570 \\
\hline \multicolumn{2}{|l|}{ Empresa com dívidas } & \multicolumn{2}{|c|}{ Empresa sem capital de giro } \\
\hline $\mathrm{R}=$ Lucros retidos/vendas & -0.774 & $\mathrm{R}=$ Lucros retidos/vendas & -1.119 \\
\hline $\mathrm{T}=$ Ativo circulante/vendas & 0.351 & $\mathrm{~T}=$ Ativo circulante/vendas & 0.374 \\
\hline Equilíbrio de crescimento $\mathrm{G}=\mathrm{R} / \mathrm{T}$ & -2.202 & Equilíbrio de crescimento $\mathrm{G}=\mathrm{R} / \mathrm{T}$ & -2.991 \\
\hline \multicolumn{2}{|l|}{ Empresa sem dívidas } & \multicolumn{2}{|c|}{ Empresa com ciclo financeiro excessivo } \\
\hline $\mathrm{R}=$ Lucros retidos/vendas & 0.187 & $\mathrm{R}=$ Lucros retidos/vendas & 0.000 \\
\hline T=Ativo circulante/vendas & 0.414 & $\mathrm{~T}=$ Ativo circulante/vendas & 1.034 \\
\hline Equilíbrio de crescimento $\mathrm{G}=\mathrm{R} / \mathrm{T}$ & 0.451 & Equilíbrio de crescimento $\mathrm{G}=\mathrm{R} / \mathrm{T}$ & 0.000 \\
\hline
\end{tabular}

Fonte: Dados da pesquisa.

\subsection{TRADING}

Walsh (2004, p. 138) afirma que o termo overtrading utiliza-se para

Descrever uma situação em que não há recursos suficientes no balanço para manter o nível de negócio existente. Aparece em uma empresa que tenha crescido demasiado depressa ou que tenha sido subfinanciada inicialmente. Os sintomas são uma constante escassez de dinheiro para satisfazer as necessidades quotidianas. Há o perigo de falência. Provavelmente a única solução para essa situação é uma injeção de fundos líquidos a longo prazo.

Trata-se da situação conhecida também por "efeito tesoura". O termo trading (T) ou nível de negócio exprime a situação de recursos suficientes no balanço para a continuidade dos negócios.

O indicador do nível de negócios ou trading (T), com base em Walsh (2004, p. 139), é assim calculado:

$$
T=1+\frac{A C-P C}{V}
$$

Onde:

T é igual ao Trading ou nível de negócio;

AC é o Ativo Circulante;

PC é o Passivo Circulante; e

V é Vendas. 
Um $\mathrm{T}=1$ significa que a empresa tem um capital circulante líquido (ou fundo de maneio) adequado ao desenvolvimento dos negócios.

O Quadro 3 mostra alguns exemplos de índices de trading $(\mathrm{T})$ calculados com base nas demonstrações financeiras extraídas de Morante e Jorge (2010).

Quadro 3 - Alguns índices de trading (T)

\begin{tabular}{|c|c|c|c|}
\hline \multicolumn{4}{|c|}{ Trading } \\
\hline \multicolumn{2}{|c|}{ Empresa com lucros } & \multicolumn{2}{|c|}{ Empresa com excesso de custos e despesas } \\
\hline Trading $=1-[(A C-E L P) / V]$ & 1.627 & Trading $=1-[($ AC-ELP)/V] & 1.432 \\
\hline \multicolumn{2}{|l|}{ Empresa com prejuízos } & \multicolumn{2}{|c|}{ Empresa com capital de giro } \\
\hline Trading $=1-[(\mathrm{AC}-\mathrm{ELP}) / \mathrm{V}]$ & 0.959 & Trading $=1-[(\mathrm{AC}-\mathrm{ELP}) / \mathrm{V}]$ & 1.133 \\
\hline \multicolumn{2}{|c|}{ Empresa com dívidas } & \multicolumn{2}{|c|}{ Empresa sem capital de giro } \\
\hline Trading $=1-[(A C-E L P) / V]$ & 0.666 & Trading $=1-[(\mathrm{AC}-\mathrm{ELP}) / \mathrm{V}]$ & 0.191 \\
\hline \multicolumn{2}{|c|}{ Empresa sem dívidas } & \multicolumn{2}{|c|}{ Empresa com ciclo financeiro excessivo } \\
\hline rading $=1-[(A C-E L P) / V]$ & 1.243 & Trading $=1-[(A C-E L P) / V]$ & 1.313 \\
\hline
\end{tabular}

É importante observar que a "empresa sem capital de giro" é a que apresenta menor índice T; A "empresa com prejuízo" e a "empresa com dívidas" também apresentam fraco desempenho em relação ao indicador $\mathrm{T}$.

\subsection{ISF}

O indicador de sustentabilidade financeira (ISF) é um indicados complexo que faz a junção dos índices acima apresentados da seguinte forma:

$$
I S F=\frac{\left(A F^{*} E C\right)+T}{2}
$$

Onde:

ISF é o Índice de Sustentabilidade Financeira e AF é a Autonomia Financeira calculada por :

$$
A F=\frac{\frac{L A I R+D F}{5 * D F}+\frac{P}{2 *(P C+P N C)}}{2}
$$

EC é o Equilíbrio do Crescimento dado por $E C=\frac{L R}{A C}$;

T é Trading ou Nível de Negócio dado por $T=1+\frac{A C-P C}{V}$

Nesse índice, o produto (AF*EC) mostra a sustentabilidade decorrente dos capitais próprios. $\mathrm{O}$ índice $\mathrm{AF}$ mostra quanto as despesas financeiras são cobertas pelas operações que 
as originam e a relação dos capitais próprios em relação aos capitais de terceiros; e o índice EC indica o quanto o crescimento é financiado por recursos próprios. Esse produto é adicionado ao índice de trading ou ao nível de negócio que se refere ao capital circulante líquido, adequado ao desenvolvimento dos negócios.

Já que os valores do ISF podem ser diversos, é recomendável haver um acordo quanto ao que é um valor fraco e forte, conforme afirma Davis (1976, p. 70). Seguindo a convenção desse autor, são adotadas as expressões utilizadas no Quadro 4.

Quadro 4 - Convenção para descrever resultados quanto ao grau de sustentabilidade financeira
\begin{tabular}{|l|l|}
\hline \multicolumn{2}{|c|}{ Indicador de Sustentabilidade Financeira -ISF } \\
\hline Valor obs ervado & \multicolumn{1}{c|}{ Interpretação adequada } \\
\hline 1,00 ou mais & Sustentabilidade plena \\
\hline 0,7 a 0,99 & Sustentabilidade substancial \\
\hline 0.5 a 0,69 & Sustentabilidade moderada \\
\hline 0.3 a 0,49 & Sustentabilidade baixa \\
\hline Abaixo de 0,3 & Sustentabilidade desprezível \\
\hline Fonte: Adaptado de Davis (1976, p. 70$)$.
\end{tabular}

O Quadro 5 mostra alguns exemplos de ISF com base nas demonstrações financeiras extraídas de Morante e Jorge (2010). É importante observar que a "empresa sem capital de giro" é a que apresenta menor índice T. A "empresa com prejuízo" e a "empresa com dívidas" também apresentam fraco desempenho em relação ao indicador $T$.

Um ISF $>1$, por seu turno, significa que a empresa tem despesas financeiras adequadamente cobertas pelas operações que as originam; um patrimônio líquido igual ou superior aos exigíveis; que tem o crescimento financiado adequadamente por recursos internos e que há capital circulante líquido adequado ao desenvolvimento dos negócios

Quadro 5 - Alguns índices ISF

\begin{tabular}{|c|c|c|c|}
\hline \multicolumn{4}{|c|}{ Índice de Sustentabilidade Financeira } \\
\hline \multicolumn{2}{|c|}{ Empresa com lucros } & \multicolumn{2}{|c|}{ Empresa com excesso de custos e despesas } \\
\hline Autonomia Financeira $=$ & 1.653 & Autonomia Financeira $=$ & 0.374 \\
\hline Equilíbrio de crescimento $\mathrm{G}=\mathrm{R} / \mathrm{T}$ & 0.721 & Equilíbrio de crescimento $\mathrm{G}=\mathrm{R} / \mathrm{T}$ & -1.748 \\
\hline Trading=1-[(AC-ELP)/V] & 1.627 & Trading $=1-[(\mathrm{AC}-\mathrm{ELP}) / \mathrm{V}]$ & 1.432 \\
\hline Indice Sustentabilidade Financeira & 1.409 & Indice Sustentabilidade Financeira & 0.389 \\
\hline \multicolumn{2}{|l|}{ Empresa com prejuízos } & \multicolumn{2}{|l|}{ Empresa com capital de giro } \\
\hline Autonomia Financeira $=$ & -0.020 & Autonomia Financeira $=$ & 0.535 \\
\hline Equilíbrio de crescimento $\mathrm{G}=\mathrm{R} / \mathrm{T}$ & 0.000 & Equilíbrio de crescimento $\mathrm{G}=\mathrm{R} / \mathrm{T}$ & 0.570 \\
\hline Trading $=1-[(\mathrm{AC}-\mathrm{ELP}) / \mathrm{V}]$ & 0.959 & Trading $=1-[(\mathrm{AC}-\mathrm{ELP}) / \mathrm{V}]$ & 1.133 \\
\hline Indice Sustentabilidade Financeira & 0.479 & Indice Sustentabilidade Financeira & 0.719 \\
\hline \multicolumn{2}{|l|}{\begin{tabular}{|l} 
Empresa com dívidas \\
\end{tabular}} & \multicolumn{2}{|l|}{\begin{tabular}{|r|} 
Empresa sem capital de giro \\
\end{tabular}} \\
\hline Autonomia Financeira $=$ & 0.068 & Autonomia Financeira $=$ & -0.014 \\
\hline Equilibrio de crescimento $\mathrm{G}=\mathrm{R} / \mathrm{T}$ & -2.202 & Equilíbrio de crescimento $\mathrm{G}=\mathrm{R} / \mathrm{T}$ & -2.991 \\
\hline Trading $=1-[(\mathrm{AC}-\mathrm{ELP}) / \mathrm{V}]$ & 0.666 & Trading $=1-[(\mathrm{AC}-\mathrm{ELP}) / \mathrm{V}]$ & 0.191 \\
\hline Indice Sustentabilidade Financeira & 0.258 & Indice Sustentabilidade Financeira & 0.116 \\
\hline \multicolumn{2}{|l|}{$\begin{aligned} \text { Empresa sem dívidas } \\
\end{aligned}$} & \multicolumn{2}{|c|}{ Empresa com ciclo financeiro excessivo } \\
\hline Autonomia Financeira $=$ & 3.099 & Autonomia Financeira= & 0.389 \\
\hline Equilíbrio de crescimento $\mathrm{G}=\mathrm{R} / \mathrm{T}$ & 0.451 & Equilíbrio de crescimento $\mathrm{G}=\mathrm{R} / \mathrm{T}$ & 0.000 \\
\hline Trading $=1-[(\mathrm{AC}-\mathrm{ELP}) / \mathrm{V}]$ & 1.243 & Trading $=1-[(\mathrm{AC}-\mathrm{ELP}) / \mathrm{V}]$ & 1.313 \\
\hline Indice Sustentabilidade Financeira & 1.321 & Indice Sustentabilidade Financeira & 0.656 \\
\hline
\end{tabular}

Fonte: Dados da pesquisa. 


\section{Metodologia}

\subsection{População e Amostra}

A população foi constituída por pequenas empresas da região do município de Campinas. A amostra foi constituída de 41 micro e pequenas empresas contabilmente estruturadas com os clientes dos escritórios de contabilidade "Seu" e "Contec" de Campinas. Justifica-se a escolha desse tipo de empresa, pois é o que mais sofre com falhas na administração financeira e o que leva ao insucesso do empreendimento (MATIAS; LOPES JR, 2002).

\subsection{Coleta de Dados}

Os dados foram coletados das demonstrações financeiras das empresas pesquisadas e foram estratificados de acordo com o "tipo" de empresa, considerando-se:

- empresa com lucros se Resultado do Exercício $>0$ e Empresa com prejuízo se Resultado do Exercício < 0;

- empresa com dívidas se Patrimônio Liquido $<0$ e Empresa sem dívidas se Patrimônio Liquido $>0$;

- empresa com excesso de custos e despesas se Lucro Operacional <0;

- empresas com capital de giro se Ativo Circulante > Passivo Circulante;

- empresas sem capital de giro se Ativo Circulante $<$ Passivo Circulante.

É importante destacar que uma empresa pode ser enquadrada em dois ou mais "tipos".

\subsection{Hipóteses Testadas}

As hipóteses testadas, formuladas com base nos estudos de Morante e Jorge (2010), apresentadas na versão de hipótese alternativa, são as seguintes:

- $\mathrm{H}_{\mathrm{a} 1}$ : o indicador de Autonomia Financeira (AF) das empresas com lucros é predominantemente $>1$;

- $\mathrm{H}_{\mathrm{b} 1}$ : o indicador de Autonomia Financeira (AF) das empresas com prejuizos é predominantemente $<0,3$;

- $\mathrm{H}_{\mathrm{h} 1}$ : o indicador de Equilíbrio do Crescimento (EC) das empresas com lucros é predominantemente $>1$; e

- $\mathrm{H}_{\mathrm{p} 1}$ : o indicador de Trading (T) das empresas com prejuízos é predominantemente $<0,5$.

\subsection{Instrumentos Analíticos}

As técnicas analíticas utilizadas basicamente constituem-se de descritores estatísticos usualmente fornecidos por "pacotes", como o Minitab R.14 e o BioEstat 5.0: média, desvio 
padrão, mínimo e máximo. Cabe ressaltar que as variáveis são consideradas variáveis qualitativas de razão, pelo que é possível aplicar testes e estatísticas paramétricos.

Para se fazer o teste binomial, para duas proporções, foi utilizado o BioEstat 5.0. Esse teste destina-se a testar a diferença entre duas proporções amostrais independentes, procurando-se determinar se a diferença $(\mathrm{p} 1-\mathrm{p} 2)$, a qual é de tal grandeza que permite rejeitar a hipótese de nulidade. $\mathrm{O}$ tamanho de cada amostra deve ser suficiente para a devida aproximação da distribuição binomial à curva normal, ou seja, quando atendidas duas condições: $\mathrm{n}_{1} \mathrm{p}_{1} \mathrm{q}_{1} \geq 5$ e $\mathrm{n}_{2} \mathrm{p}_{2} \mathrm{q}_{2} \geq 5$.

\subsection{Operacionalização da Pesquisa}

A pesquisa foi operacionalizada seguindo as etapas a seguir:

1) Obtenção dos demonstrativos contábeis junto aos escritórios de contabilidade.

2) Agrupamento das demonstrações contábeis de acordo com as características da presente pesquisa: empresas com lucro, empresa com prejuízo, empresa com dívidas, empresa sem dívidas, empresa com excesso de custos e despesas, empresas com capital de giro e empresas sem capital de giro.

3) Apuração do índicador de Autonomia Financeira (AF).

4) Apuração do indicador de Equilíbrio do Crescimento (EC).

5) Apuraração do indicador de Trading (T).

6) Apuração do Indicador de Sustentabilidade Financeira (ISF).

7) Tabulação dos resultados dos indicadores.

8) Teste das hipóteses utilizando-se os pacotes estatísticos Minitab R.14 e BioEstat 5.0, especialmente para o teste binomial.

\section{Resultados}

Os resultados encontrados estão sintetizados em diversas tabelas e tais tabelas mostram os níveis de significância obtidos para a diferenciação de cada variável, considerando as 41 entidades investigadas sob diversas óticas.

\subsection{Níveis de Significância}

A Tabela 1 mostra que os indicadores Autonomia Financeira (AF), Equilíbrio do crescimento (EC), Trading (T) e Indicador de Sustentabilidade Financeira (ISF) diferem significativamente quando calculados para empresas com e sem lucros, isto é, esses indicadores são significativamente diferentes ao nível de significância $\alpha$ quando se considera as empresas estratificadas em empresas com lucros e empresas sem lucros. 
Tabela 1 - Síntese dos níveis de significância dos índices AF, EC, T e ISF de empresas com e sem Lucros

\begin{tabular}{|c|c|}
\hline Análises referentes às empresas com e sem Lucros & $\mathbf{A}$ \\
\hline $\begin{array}{l}\text { O indicador de Autonomia Financeira (AF) das empresas com lucros } \\
\text { difere significativamente das empresas sem lucro (prejuízo). }\end{array}$ & 0.010 \\
\hline $\begin{array}{l}\text { O indicador de Equilíbrio do Crescimento (EC) das empresas com lucros } \\
\text { difere significativamente das empresas sem lucro (prejuízo). }\end{array}$ & 0.010 \\
\hline $\begin{array}{l}\text { O indicador de Trading (T) das empresas com lucros difere } \\
\text { significativamente das empresas sem lucro (prejuízo). }\end{array}$ & 0.050 \\
\hline $\begin{array}{l}\text { O indicador de Sustentabilidade Financeira (ISF) das empresas com } \\
\text { lucros difere significativamente das empresas sem lucro (prejuízo). }\end{array}$ & 0.001 \\
\hline $\begin{array}{l}\text { Legenda: Com = valor médio obtido pelas empresas com a característica a } \\
\text { obtido pelas empresas sem a característica assinalada; } \alpha=\text { nível de signific } \\
\text { diferença significativa entre as médias "com" e "sem". }\end{array}$ & ada; $s$ \\
\hline
\end{tabular}

A Tabela 2 mostra que os indicadores Autonomia Financeira (AF), Equilíbrio do crescimento (EC), Trading (T) e Indicador de Sustentabilidade Financeira (ISF) diferem significativamente quando calculados para empresas com e sem dívidas: isto é, esses indicadores são significativamente diferentes ao nível de significância $\alpha$ quando se considera as empresas estratificadas em empresas com dívidas e empresas sem dívidas.

Tabela 2 - Síntese dos níveis de significância dos índices AF, EC, T e ISF das empresas com e sem Dívidas

\begin{tabular}{|c|c|}
\hline Análises referentes às empresas com e sem Dívidas & $\mathbf{A}$ \\
\hline $\begin{array}{l}\text { O indicador de Autonomia Financeira (AF) das empresas com dívidas } \\
\text { difere significativamente das empresas sem dívidas. }\end{array}$ & 0.001 \\
\hline $\begin{array}{l}\text { O indicador de Equilíbrio do Crescimento (EC) das empresas com } \\
\text { dívidas difere significativamente das empresas sem dívidas. }\end{array}$ & 0.050 \\
\hline $\begin{array}{l}\text { O indicador de Trading } \mathbf{( T )} \text { das empresas com dívidas difere } \\
\text { significativamente das empresas sem dívidas. }\end{array}$ & 0.001 \\
\hline $\begin{array}{l}\text { O indicador de Sustentabilidade Financeira (ISF) das empresas com } \\
\text { dívidas difere significativamente das empresas sem dívidas. }\end{array}$ & 0.001 \\
\hline $\begin{array}{l}\text { Legenda: Com = valor médio obtido pelas empresas com a característica } \\
\text { obtido pelas empresas sem a característica assinalada; } \alpha=\text { nível de signi } \\
\text { diferença significativa entre as médias "com" e "sem". }\end{array}$ & $\begin{array}{l}\text { lada; } \text { Sem = valor médio } \\
\text { a no caso de se observar }\end{array}$ \\
\hline
\end{tabular}

A Tabela 3 mostra que os indicadores Autonomia Financeira (AF), Equilíbrio do crescimento (EC), Trading (T) e Indicador de Sustentabilidade Financeira (ISF) diferem significativamente quando calculados para empresas com e sem excessos de custos e despesas, isto é, esses indicadores são significativamente diferentes ao nível de significância $\alpha$ quando se considera as empresas estratificadas em empresas com excesso de custos e despesas e empresas sem tais excessos. 
Tabela 3 - Síntese dos níveis de significância dos índices AF, EC, T e ISF das empresas com e sem Excesso de Custos e Despesas

\begin{tabular}{|c|c|}
\hline $\begin{array}{l}\text { Análises referentes às empresas com e sem Excesso de Custos e } \\
\text { Despesas }\end{array}$ & A \\
\hline $\begin{array}{l}\text { O indicador de Autonomia Financeira (AF) das empresas com excesso de } \\
\text { custos e despesas difere significativamente das empresas sem e com } \\
\text { excesso de custos e despesas. }\end{array}$ & 0.001 \\
\hline $\begin{array}{l}\text { O indicador de Equilíbrio do Crescimento (EC) das empresas com } \\
\text { excesso de custos e despesas difere significativamente das empresas sem e } \\
\text { com excesso de custos e despesas. }\end{array}$ & 0.050 \\
\hline $\begin{array}{l}\text { O indicador de Trading (T) das empresas com excesso de custos e despesas } \\
\text { difere significativamente das empresas sem e com excesso de custos e } \\
\text { despesas. }\end{array}$ & 0.050 \\
\hline $\begin{array}{l}\mathrm{O} \text { indicador de Sustentabilidade Financeira (ISF) das empresas com } \\
\text { excesso de custos e despesas difere significativamente das empresas sem e } \\
\text { com excesso de custos e despesas. }\end{array}$ & 0.001 \\
\hline $\begin{array}{l}\text { Legenda: Com = valor médio obtido pelas empresas com a característica as } \\
\text { obtido pelas empresas sem a característica assinalada; } \alpha=\text { nível de significâ } \\
\text { diferença significativa entre as médias "com" e "sem". }\end{array}$ & \\
\hline
\end{tabular}

A Tabela 4 mostra que os indicadores Trading (T) e Indicador de Sustentabilidade Financeira (ISF) diferem significativamente quando calculados para empresas com e sem capital de giro, isto é, esses indicadores são significativamente diferentes ao nível de significância $\alpha$ quando se considera as empresas estratificadas em empresas com capital de giro e empresas sem capital de giro.

Entretanto, dois indicadores apresentaram resultados não significativos: Autonomia Financeira (AF) e Equilíbrio do Crescimento (EC), ou seja, quando se estratificou as empresas em relação ao seu capital de giro (com e sem), os resultados calculados no que se refere à $\mathrm{AF}$ e EC não se distinguem estatisticamente.

\section{Tabela 4 - Síntese dos níveis de significância dos índices AF, EC, T e ISF das empresas com e} sem Capital de Giro

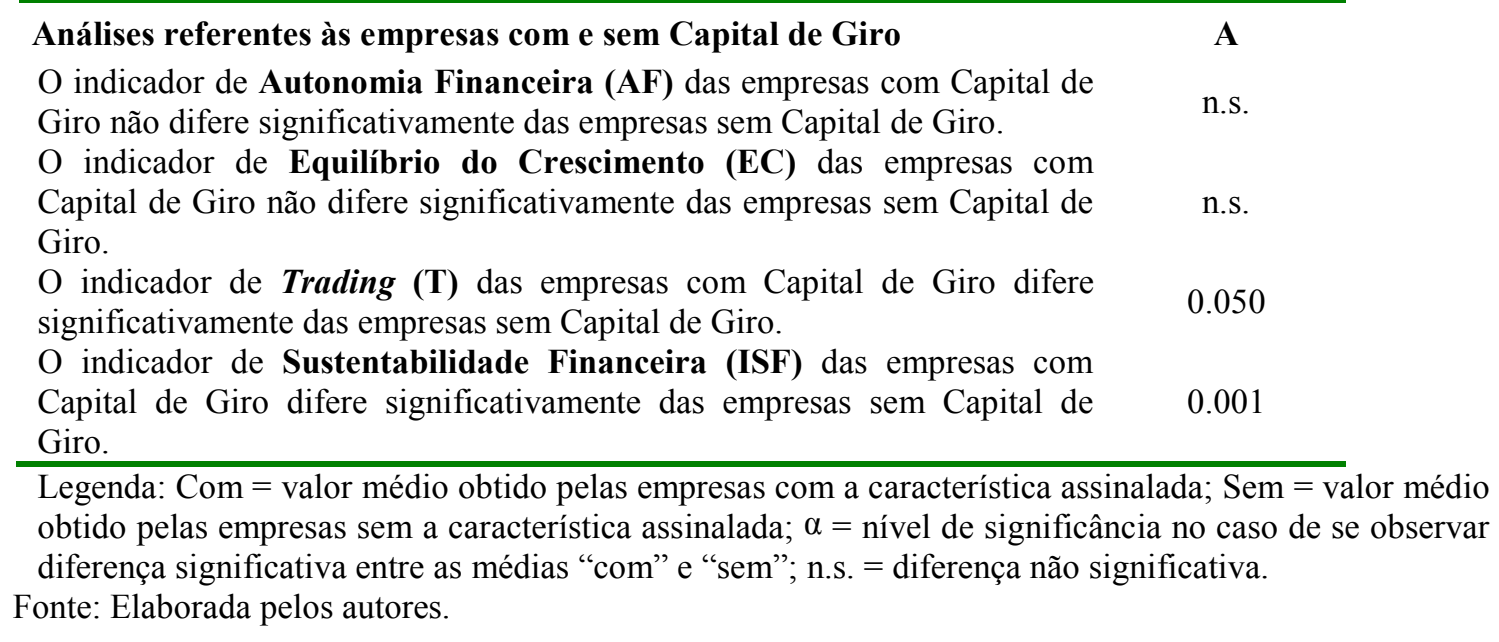




\subsection{Testes das Hipóteses}

Os testes das hipóteses apresentaram os seguintes resultados:

- Ha1: o indicador de Autonomia Financeira (AF) das empresas com lucros é predominantemente $>1$;

- Hipótese aceita: apenas $10 \%$ dos indicadores de autonomia financeira das empresas com lucros (AFCL) são menores do que 1. A média desse indicador foi de 1,41 ;

- Hb1: o indicador de Autonomia Financeira (AF) das empresas com prejuízos é predominantemente $<0,3$;

- Hipótese rejeitada: $30 \%$ dos indicadores de autonomia financeira das empresas com prejuízos (AFCP) são maiores do que 0,3. A média do indicador, entretanto, foi de 0,118 ;

- Hh1: o indicador de Equilíbrio do Crescimento (EC) das empresas com lucros é predominantemente $>1$;

- Hipótese aceita: apenas $10 \%$ dos indicadores de equilíbrio do crescimento das empresas com lucros (ECCP) são menores do que 1. A média desse indicador foi de 1,46 ;

- Hp1: o indicador de Trading (T) das empresas com prejuízos é predominantemente $<0,5$; e

- Hipótese rejeitada: $23 \%$ dos indicadores de trading das empresas com prejuízos (AFCP) são maiores do que 0,5. A média do indicador, entretanto, foi de 0,3241 .

\subsection{Análise do Indicador de Sustentabilidade Financeira (ISF)}

Dutra (2005) considera um conjunto de dimensões que podem ser aplicadas ao indicador proposto. A avaliação do indicador, segundo esse autor, considera os seguintes aspectos:

- Grau de Personalização, que identifica o nível de particularização da metodologia, isto é, a potencialidade em atender as necessidades específicas de uma organização em particular. Neste estudo, foi considerado elevado, já que o indicador proposto pode calcular o nível de sustentabilidade financeira de uma empresa específica.

- Grau de não Ambiguidade, que identifica se a metodologia não é ambígua, considerando-se sua estrutura; a possibilidade de mais de uma forma de interpretação ou de duplo sentido evidencia um grau elevado de ambiguidade, denotando ausência de clareza e de compreensibilidade. Sendo assim, esse indicador foi considerado baixo, ou seja, de pouca ambiguidade.

- O Grau de Priorização, que identifica se a metodologia enfatiza ou desconsidera certas medidas de desempenho ou áreas da organização, em detrimento de outras, ignorando ou, ao contrário, dando importância excessiva a algum indicador ou aspecto específico. Pela constituição do indicador 
proposto, que leva em conta aspectos específicos, pode-se considerar elevado o grau de priorização.

- Grau de Flexibilidade, que identifica a capacidade para atender a todo e qualquer tipo de organização, de forma macro ou micro, considerando-se sua estrutura organizacional. Na medida em que o indicador proposto aplica-se a organização de qualquer porte, o grau de flexibilidade pode ser considerado elevado.

- Grau de Geração de Conhecimento, que identifica se, no decorrer da implementação da metodologia, ocorre a geração de conhecimento, aqui entendido como capacidade para promover conscientização, envolvimento e responsabilidade dos indivíduos, direta ou indiretamente envolvidos no processo; cumpre fazer uma distinção entre conhecimento como um processo cognitivo complexo e abrangente, em oposição a um simples processo de familiarização resultante de treinamento. Essa característica é das mais relevantes no indicador proposto, dado que não apenas dá uma síntese da situação quanto à sustentabilidade financeira da empresa mas, também, oferece a possibilidade de "explicar" o resultado por meio dos demais indicadores associados aos constructo: indicadores de Autonomia Financeira (AF), Equilíbrio do crescimento (EC) e Trading (T)

- Grau de Geração de Aperfeiçoamento, que identifica se a metodologia, considerando-se sua estrutura e seus procedimentos operacionais, permite, de maneira estruturada, a geração de aperfeiçoamento do desempenho organizacional em decorrência da identificação dos pontos fracos. O grau é elevado, pois é possível elencar, de forma estruturada, medidas tendentes a melhorar o desempenho do indicador considerado. Isso pode ser observado pela constituição do indicador, como mostra a expressão (10), a seguir.

$$
I S F=\frac{\left(A F^{*} E C\right)+T}{2}
$$

ou:

$$
I S F=\frac{1}{2}\left[\left(\frac{L A I R+D F}{10 * D F}+\frac{P}{4 *(P C+P N C)}\right) *\left(\frac{L R}{A C}\right)+\left(1+\frac{A C-P C}{V}\right)\right]
$$

Onde:

LAIR é o Lucro antes do IR e da CS;

DF são as despesas financeiras;

P é o total do passivo;

PC é o Passivo Circulante;

PNC é o Passivo Não Circulante. LR é o total de lucros retidos;

AC é o Ativo Circulante; e

$\mathrm{V}$ é igual ao total de Vendas. 
O quadro 6, a seguir, mostra um resumo da avaliação feita anteriormente.

\section{Quadro 6 - Avaliação das características do indicador proposto}

\begin{tabular}{|l|c|c|c|c|c|}
\hline \multirow{2}{*}{\multicolumn{1}{c|}{ Avaliação de indicador }} & \multicolumn{2}{|c|}{ Baixo } & \multicolumn{4}{|c|}{ Alto } \\
\cline { 2 - 6 } & $\mathbf{1}$ & $\mathbf{2}$ & $\mathbf{3}$ & $\mathbf{4}$ & $\mathbf{5}$ \\
\hline Grau de personalização & & & & & $\mathrm{x}$ \\
\hline Grau de não ambiguidade & & & & $\mathrm{x}$ & \\
\hline Grau de priorização & & & & & $\mathrm{x}$ \\
\hline Grau de flexibilidade & & & & & $\mathrm{x}$ \\
\hline Grau de geração de conhecimento & & & & & $\mathrm{x}$ \\
\hline Grau de geração de aperfeiçoamento & & & & & $\mathrm{x}$ \\
\hline
\end{tabular}

Fonte: Adaptado de Dutra (2005).

Dessa forma, evidencia-se que o ISF é um indicador específico para avaliar a sustentabilidade financeira de uma empresa, constituído sobre outros indicadores que dão ao analista uma síntese da situação quanto à sustentabilidade financeira da empresa mas, também, oferece a possibilidade de "explicar" o resultado por meio dos demais indicadores associados aos constructo: indicadores de Autonomia Financeira (AF), Equilíbrio do crescimento (EC) e Trading (T). O indicador proposto possui um elevado grau de geração de aperfeiçoamento, na medida em que consegue elencar, de forma estruturada, medidas tendentes a melhorar o desempenho do indicador considerando.

\section{Conclusões e Recomendações}

A pesquisa abordou a sustentabilidade financeira, considerando que ela é imprescindível para as empresas independendo de seu porte. Para as micro e pequenas (MPEs), esse fator é primordial para a longevidade de suas atividades. Considerou-se que uma a atividade sustentável qualquer é aquela que pode ser mantida por um longo período indeterminado de tempo, ou seja, para sempre, de forma a não se esgotar nunca, apesar dos imprevistos que podem vir a ocorrer durante este período (PHILIPPI, 2001 apud ARAÚJO et al., 2006).

Cabe destacar que os indicadores aqui testados apresentam diferenças significativas nos casos das empresas terem ou não dada característica. Por exemplo, no que concerne à autonomia financeira (AF), a média dos indicadores das empresas com lucros difere significativamente das empresas sem lucros; o mesmo se pode dizer com relação às dívidas, ao excesso de custos e despesas e a posse ou não de capital de giro. Foi com referência a essa última característica que se observaram os únicos testes que não apresentaram diferença significativa: em relação ao indicador de Autonomia Financeira (AF) e em relação ao indicador de Equilíbrio do Crescimento (EC).

A autonomia financeira foi estruturada com base em Walsh (2004, p. 144), no sentido de dimensionar a capacidade de resistência de uma empresa aos contratempos operacionais, e levou em conta basicamente dois indicadores: um indicador derivado da cobertura de juros e outro do rácio da autonomia. É possível que o indicador da autonomia financeira seja mais bem dimensionado se for levado em conta, também, o valor presente líquido dos fluxos de 
caixa futuros esperados e decorrentes das operações da empresa, tendo como taxa de desconto apropriada o custo médio ponderado de capital (CARNEIRO; SILVA, 2010)

Deve-se, entretanto, levar em conta a afirmação de Dearden (1969), para quem o uso de medidas de valor presente ainda sofre algumas dificuldades, tais como: a decisão sobre o horizonte temporal a considerar, a imprecisão das estimativas futuras e a imprecisão na estimação da taxa de desconto. Outra crítica às medidas de valor presente, dessa vez, feita por Barney e Hesterly (2007), é que elas, à semelhança das medidas usuais de retorno contábilfinanceiro, também não levariam adequadamente em conta os efeitos futuros dos ativos intangíveis, como a lealdade dos clientes, por exemplo, a menos que eles se reflitam no desempenho futuro esperado

Para a interpretação do resultado obtido do ISF, achou-se recomendável haver um acordo quanto ao que é um valor fraco e forte e adotou-se a convenção mostrada no quadro 4. Com isso, uniformiza-se a linguagem referente ao valor calculado, que pode ir de grau "desprezível" a "pleno".

Assim, este trabalho, pelos seus resultados, recomenda que novas pesquisas sejam feitas. Estudos com maior número de empresas e com empresas de todos os portes econômicos podem, inclusive, mostrar que efetivamente o ISF aqui proposto é um indicador útil e altamente aplicável. Outros estudos com empresas que faliram podem mostrar a evolução do ISF dessas empresas em períodos anteriores. Por outro lado, pesquisas mais aprofundadas podem mostrar que pode haver diferença significativa entre os ISFs dos diversos setores econômicos, bem como dos diversos tipos de empresas: serviços, comércio e indústria.

\section{Referências}

ALTMAN, Edward I. Financial Ratios, Discriminant Analysis and the Prediction of Corporate Bankruptcy, Journal of Finance, v. 23, n.4. p. 589-609, set. 1968.

ARAÚJO, Edgilson Tavares. O Desafio da Sustentabilidade nas APAEs: Noções sobre Captação de Recursos e Elaboração de Projetos Sociais. FEAPAES Informa - Boletim Informativo da Federação das APAEs do Estado do Espírito Santo, Vitória, p. 4, 02 mar. 2003.

BARNEY, Jay B.; HESTERLY, William S. Administração Estratégica e Vantagem Competitiva. São Paulo: Pearson Prentice Hall, 2007.

BARTUSKA, T. J.; KAZIMEE, B. A.; OWEN, M. S. Defining sustainability. In: Community sustainability: a comprehensive urban regenerative process - a proposal for Pullman Washington, USA. Washington: School of Architecture/Washington State University, 1998.

BEAUD, M. Arte da tese. Rio de Janeiro: Bertrand, 1997.

BEAVER, W. Financial ratios as predictors of failure: empirical search in accounting: selected studies. Journal of Accounting Research, n. 4, p. 71-111, jan. 1966. 
BM\&FBOVESPA. Demonstrações Financeiras (548 empresas). Disponível em: $<$ http://www.bmfbovespa.com.br/>. Acesso em: 27 jul. 2010

BOTUCATU TEXTIL SA. Demonstrações Financeiras do Exercício de 2008. Disponível em: < http://www.bmfbovespa.com.br/ >. Acesso em: 27 jul. 2010

BRUNTLAND, G. Our Common Future: The World Commission on Environment and Development. Oxford: Oxford University Press, 1987.

BRKLACICH, M.; BRYANT, C. R.; SMIT, B. Review and appraisal of concept of sustainable food production systems. Environmental Management, New York, v. 15, n. 1, p.1-14. 1991.

CARNEIRO, Jorge; SILVA, Jorge Ferreira. Medidas contábeis-financeiras como indicadores de desempenho organizacional: análise crítica de sua conceituação e operacionalização. Gesta - Revista Eletrônica de Gestão de Negócios, v. 6, n. 3, jul./ago. 2010.

CAVALCANTI, C. Sustentabilidade da economia: paradigmas alternativos de realização econômica. In: CAVALCANTI, C. (Org.). Desenvolvimento e natureza: estudos para uma sociedade sustentável. São Paulo: Cortez, 2003. p. 153-176.

CONWAY, G. R. Agroecosystem analysis for research and development. Bangkok: Winrock International, 1986.

DAVIS, J. A. Levantamento de dados em sociologia. Rio de Janeiro: Zahar, 1976.

DEARDEN, J. The Case Against ROI Control. Harvard Business Review, v. 47, n. 3, p. 124-135. 1969.

DOVERS, S. R.; HANDMER, J. W. Contradictions in sustainability. Environmental Management, New York, v. 20, n. 3, p. 217-222. 1993.

DUTRA, Ademar. Metodologias para avaliar o desempenho organizacional: revisão e proposta de uma abordagem multicritério. Revista Contemporânea de Contabilidade, Florianópolis, n.3, p. 25-56, jan./jun. 2005.

FRIEDMAN, T. L. Quente, plano e lotado. Rio de Janeiro: Objetiva, 2010.

HRONEC, S. Sinais Vitais. São Paulo: Makron, 1994.

LIVERMAN, D. M. et al.Global sustainability: toward measurement. Environmental Management, New York, v. 12, n. 3, p. 133-143. 1988. 
MARTINS, Gilberto A.; SILVA, Renata B. Costa. Plataforma teórica - trabalhos dos $3^{\circ}$ e $4^{\circ}$ congressos USP de controladoria e contabilidade: Um estudo bibliométrico. In:

CONGRESSO USP DE CONTROLADORIA E CONTBILIDADE, 5., 2005, São Paulo.

Anais... São Paulo: USP, 2005.

MATIAS, A. B.; LOPES JR., F. Administração financeira nas empresas de pequeno porte. São Paulo: Manole, 2002.

MOORE, J.A.; JOHNSON, J. M. Transportation, land use and sustainability: what is "sustainability"? Tampa: Center for Urban Transportation Research, 1994.

MORANTE, A. S.; JORGE, F. T. Administração Financeira. São Paulo: Atlas, 2010.

RAMOS FILHO, A. C. Gestão de Pessoas em organizações sustentáveis. In: ENANPAD, 20., 2008, Rio de Janeiro. Anais... Rio de Janeiro: ANPAD, 2000.

ROVER, Suliani; BORBA, José Alonso; BORGERT, Altair. Como as Empresas Classificadas no Índice de Sustentabilidade Empresarial (ISE) Evidenciam os Custos e Investimentos Ambientais? Revista de Custos e @gronegócio online, v. 4, n. 1, jan./abr. 2008.

VALADÃO JR., V. M.; MALAQUIAS, R. F.; SOUSA, E. G. Controladoria como uma opção à sustentabilidade econômica nas organizações de Terceiro Setor: o caso de uma associação.

Revista Contemporânea de Contabilidade, v. 1, n. 9, p. 131-151, jan./jun. 2008.

VELANI, Cassio Luiz; RIBEIRO, Maisa de Souza. Sustentabilidade e Contabilidade. Revista Contemporânea de Contabilidade, Florianópolis, v. 1, n. 11, p. 187-206, jan./jun. 2009.

WALSH, C. Rácios fundamentais da gestão: como analisar, comparar e controlar os números que determinam o valor da empresa. 2. ed. Lisboa: Dom Quixote, 2004. 
